\title{
The Political Preferences and Value Orientations of Irish Journalists
}

\author{
MARY P. CORCORAN \\ National University of Ireland, Maynooth
}

\begin{abstract}
There is a dearth of sociologically informed literature on Irish journalists. In her seminal paper, Kelly (1983) laid out the factors influencing the production of news in a general context, acknowledging in her analysis the limited range of research on the Irish media. She highlighted the ideological and personal preferences of journalists on the one hand, and their professional values and practices on the other as key determinants of the news agenda. However, to date no systematic study of Irish journalists has addressed these twin concerns. Drawing on data obtained from a national survey of daily news journalists in the Republic of Ireland conducted in the late 1990s, this paper offers some insight into the class position, political orientation and value system of a key group of 'meaning producers' in Irish society. In particular, the article seeks to provide insight into the professional culture of Irish journalists and their views on the relationship between the messenger, the message and the audience. This focus is apposite, given the central role played by Irish news journalists in bringing to public attention the variety of political, financial and religious scandals that engulfed Irish society in recent years. The paper concludes that Irish journalists are in the main more liberal in their views than either the professional organisations they work for or the audiences they serve.
\end{abstract}

\section{Introduction}

The relationship between the media and society has become an increasingly central concern within the social sciences. Media analysts pay attention to issues of ownership and control, the social organisation of news production, the nature of media audiences and the media's political and social effects. Historically, it has been a matter of some debate within media studies, as to whether or not the media play an agenda-setting role with regard to the formation of public opinion. Early studies, for example, focused on elections and public health campaigns, and noted a correspondence (although not a causal connection) between the significance of issues as identified by the media, and their salience to politicians and the general 
public (McCombs and Shaw 1972; Blumler and Gurevitch 1981; Martin 1981; Cook et al. 1983). These studies tend to overlook the fact that the priorities of three key constituencies - the media, the public and the policy makers - may not coalesce but may, in fact, interact in complex ways and in different directions (Rogers and Dearing 1987; McQuail 1998). While the media may not play an overt agenda-setting role, they are nevertheless deemed to be particularly effective because of their capacity to construct meanings, and to offer those constructs in a systematic way to audiences where they are likely to be incorporated to one degree or another, into personal meaning structures (Gamson and Modigliani 1989; McQuail 1998). Indeed, long before the rise of social constructivism in media studies, Schelsky (1975) had argued that journalists are the 'informing intellectuals' or 'meaning producers' in modern western societies.

A large number of national and cross-national studies have focused on the profession of journalism and journalists' organisational culture (Tuchman 1978; Schlesinger 1978; Gans 1980; MacArthur 1991; Schudson 1991). Most decisions about the day-to-day content of the media, print and electronic, are made by reporters and editors. As Tuchman (1978) has pointed out, these front-line journalists act essentially as gatekeepers. She suggests that a number of factors influence gatekeepers in making their news decisions. First, they are individuals like the rest of us, with their own interests, ideas and preferences. They have their own subjective definitions of what is news or what will appeal to the audience they have in mind. Secondly, they work within the confines of prescribed routines that are determined by their position in the organisation and the type of information the organisation requires. They are exposed to pressures from management, from their news sources, their fellow reporters and editors, other journalists and the commonly recognised standards of journalism. In the context of these structural constraints, journalists develop a news sense which enables them to make judgements not only about the newsworthiness of a given item, but also about how the reporting of that item ought to be framed. In short, journalists can behave selectively toward topics and events.

In terms of the wider context within which journalists carry out their work it is argued that content is increasingly dictated by 'the ever-present influence of the logic of market forces, [which] is key to understanding the workings of the journalistic field' (Demuijnck 2001: 165). On the other hand, Hallin (1985) suggests that the media are formally 'disconnected' from other ruling agencies because they are more concerned about their own legitimation than about furthering the legitimation of the capitalist system as a whole.

There is a dearth of sociologically informed literature on Irish journalists, although there has been no shortage of anecdotal commentary on 'the power of the Irish press', the 'Dublin 4 mind-set', 'the liberal agenda' and 'the anti-Catholic bias' of the journalism fraternity. Several high profile journalists have been forthright in their criticism of Irish journalistic practice. For example, Vincent Browne has argued that the media are 'not reflective of the full range of views and opinions 
in Irish society' (1992). John Waters goes further, arguing that the 'media in Ireland, as in most countries, are the instrument and mouthpiece of the dominant consensus' (1995). In his introduction to Media in Ireland: The Search for Diversity, Kiberd questions whether a true plurality of views could find expression within Irish print and broadcast media (1997: 7). Rapple suggests that there is a lack of diversity in the Irish media and that this can be attributed, among other factors, to the limited access to the journalist profession. Few journalists, he claims, come from poor backgrounds. This, he continues, 'possibly reflects the fact that very few people from poor backgrounds manage to get a third-level education and that is changing only slowly' (Rapple 1997: 75). In the same volume, Kiberd argues that by failing to engage in critical self-analysis, 'Irish journalists are weakening each day the thread of trust linking them and their work to the wider public' (1997: 35). This call for greater reflexivity in Irish journalism is reiterated in a subsequent volume (Kiberd 1999).

In her seminal paper, Kelly (1983) laid out the factors influencing the production of news in a general context, acknowledging in her analysis the limited range of research on the Irish media. She highlights the ideological and personal preferences of journalists on the one hand, and their professional values and practices on the other as key determinants of the news agenda. Furthermore, legal constraints in the form of censorship and libel laws have had a demonstrable chilling effect on journalists in Irish society over the years (Let In the Light 1993; Brady 1999; Corcoran and O'Brien, forthcoming). Nevertheless, Cassidy argues that the media have 'a function as a gatekeeper to the public space, setting the agenda for public discussion, defining the issues of the day, and orchestrating the participants in the resulting debates' (2001: 3). This implies that journalists take an activist role in terms of their professional work practices. Marron's study of investigative journalism in Ireland revealed that a majority of journalists surveyed believed themselves to be 'doing investigative work'. On the other hand, respondents were cognisant of the numerous obstacles to investigations in Ireland, and more than half ( 54 per cent) considered journalism in Ireland to be passive (Marron 1995: 92). This would seem to suggest that while Irish journalists aspire towards hard-nosed, investigative journalism, in practice they are often thwarted from pursing this path.

Despite the varied and vociferous prognostications on the Irish media, remarkably little data on Irish journalists has been systematically gathered by social scientists. This study has been undertaken to address concerns in relation to the ideological and political preferences of journalists on the one hand, and their professional values and practices on the other. Drawing on data obtained from a national survey of daily news journalists in the Republic of Ireland conducted in the late 1990 s, this article offers some insight into the class position, political orientation and value system of this key group of 'meaning producers' in Irish society. In particular, I want to explore the relationship between Irish journalists, aspects of the professional media culture of which they form a part, and the public audience for 
whom they frame the news. This focus is apposite, given the central role played by Irish news journalists in bringing to public attention the variety of political, financial and religious scandals that have engulfed Irish society in recent years. The late 1990s marked a watershed period for Ireland in general, and Irish journalism in particular. The Celtic Tiger brought a period of unprecedented boom to the Irish economy. At the same time, it was marked by the development of a new instrument of deliberative democracy - the tribunal of inquiry, established to investigate matters of definite public interest (Corcoran and White 2000: 186). The media went into a period of investigative overdrive, and reaped the benefits in an expansion of the media market. As Horgan has argued 'the circulation of newspapers was enhanced by the political volatility of the $1990 \mathrm{~s}$, and by the development of an even more adversarial relationship between journalists and government than had been the case hitherto' (2001: 165). Hence, at the turn of the twenty-first century Irish journalists occupy a robust position, riding high on their new-found reputation as whistle blowers willing to take on establishment figures and institutions.

\section{Methodology}

The study involved the administration of a detailed questionnaire to a national sample of Irish print and broadcasting journalists. ${ }^{1}$ The questionnaire was originally developed by a team of international scholars led by Tom Patterson of Harvard University and Wolfgang Donsbach of the University of Dresden, as part of a Media and Democracy project conducted in five other countries including Britain, the United States and Germany. An additional module, similar to the one conducted in Ireland, has also been completed in Spain. Issues explored included journalists' rights and responsibilities, their views on freedom of expression and freedom of the press, their attitudes toward the job, and their personal values and political orientations. The target survey population consisted of journalists involved in the daily news process. In terms of the study a journalist was defined as a person who makes decisions directly affecting daily news content. The category thus includes both reporters and editors. The sole criterion for inclusion was participation in daily news decisions.

Minor adjustments were made to the questionnaire in collaboration with the originators in order to frame it appropriately for the Irish sample. A number of additional questions were added as they were deemed to be of specific interest in the Irish context. The first phase of the data collection began in April 1997, and involved contacting newspaper editors and the Head of News, Radio Telef"s Éireann (RTÉ) to seek access to personnel records in order to draw up a sampling frame. Random selection was used to choose the survey population. The sample was drawn from personnel rosters obtained from five national news organisations: The Irish Independent/Evening Herald, The Irish Times, The Star, The Examiner and RTÉ Radio and Television. ${ }^{2}$ Following the protocol of the Media and Democracy 
project, the sample was stratified by medium of communication, fifty per cent of the sample was newspaper journalists, and fifty per cent broadcast journalists. ${ }^{3}$ The initial mail-out totalled 260 questionnaires. One hundred and thirty two were sent to individual journalists in the RTÉ newsroom (at the time this constituted the total population of journalists involved in daily news making) and the remainder (128 questionnaires) were distributed to journalists randomly selected from the personnel rosters of The Irish Times (45), Irish Independent/ Evening Herald (53), The Star (20) and The Examiner (10). The key advantages of the postal survey in this instance were that it offered convenience and a sense of anonymity for the interviewee, which are particularly important when respondents are being required to disclose personal and professional information. The use of the postal survey also reduced costs considerably.

Follow-up letters were sent out in July, and a final attempt was made to contact journalists who had not replied, again by letter, in September 1997. While the response rate was low, 43 per cent (112 respondents), it compares not unfavourably with response rates of 36 per cent to 51 per cent in the five other countries surveyed in 1991-3. Methodology textbooks suggest that 50 per cent response rate is adequate for postal surveys. However, it is most likely that the information age has decreased the possibility of such a response rate as people - and particularly journalists - are increasingly bombarded with unsolicited information and requests through a variety of media technologies. Nonetheless, it is surprising that the response rate is so low in Ireland and the comparison countries. This is particularly so given that we are dealing with an occupational group that might be expected to be more responsive. Journalists however, may feel similarly to other professions such as law and medicine - whose members are notoriously reticent about making personal disclosures. This may stem from a deeply held belief that their professionalism is an unimpeachable given and, therefore, is not to be questioned. It must also be noted, however, that several journalists commented on the length of the survey (more than fifty questions) which they found cumbersome. This may have been a major deterrent for people who are frequently under time pressure.

The advantages of using a postal survey outweigh the disadvantages, so long as the sample size obtained is not too low. The sample size of 112 is nevertheless robust and provides a basis for analysing aspects of Irish journalists' culture in a comparative context.

\section{Demographic profile of Irish journalists}

An age breakdown of the respondents indicates that Irish journalism is a young person's profession. The majority ( 55 per cent) of respondents questioned were aged between $25-44$ years, with a third ( 33 per cent) aged between $45-54$ years. The remaining 12 per cent of respondents were to be found in the 55-62 age group. The relative youthfulness of the profession - and the fresh perspective that is likely to be brought to bear - is not lost on those who have attained senior 
positions within Irish journalism. As one Irish editor put it: 'Young staff have totally different values. They talk about you being past your sell-by date in your middle fifties - that comes across more and more because my staff are quite young' (Fergus O'Callaghan quoted in Kenny 1994: 203). The relatively small percentage of journalists aged between 55-62 years suggests that fewer journalists work in journalism until retirement age, retiring early or making a career change before that time, or as O'Callaghan suggests, feeling a little too old for the job.

Just under a third ( 30 per cent) of Irish journalists are female. While these figures suggest that journalism is largely a male dominated profession it is noteworthy that more than two-thirds ( 70 per cent ) of female respondents were aged 45 years or under. It is therefore likely that as these younger age cohorts progress the gender breakdown in Irish journalism, as has been the case in other professions, will become more balanced. Nevertheless, it is true that few women reach the upper echelons of the profession, a fact underscored by the extensive coverage afforded to the appointment of Geraldine Kennedy as editor of The Irish Times in 2002. The status of women in journalism therefore, tends to reflect the status of women in the Irish workplace as a whole. They are increasingly visible within the profession, but are not yet fully represented at the top. The dominance of men in the media has helped create a myth about how the media are run and the manner in which journalists do their job. Kenny (1994), for example, makes reference to a 'priesthood' of journalists. Oram, in Paper Tigers (1993), writes about Irish newspapers as 'places of high drama, tension and pace, often enlivened by great good camaraderie'. In light of the 2:1 ratio of male to female journalists in Ireland, it is probably fair to surmise that male norms have historically prevailed in the news gathering process, and to that extent Irish news journalism has hitherto been largely 'men's work'. More women coming into the profession and more women progressing to senior positions within it, will challenge this perception.

Apart from the gender imbalance, the argument has also been advanced that Irish journalists are mainly drawn from a narrow range of the social class spectrum and that they therefore are likely to represent primarily their own class interests. Our data on routes into journalism provide some insight into the class backgrounds of Irish journalists. As Figure 1 demonstrates, two-thirds (67 per cent) of daily news journalists had a primary or advanced college degree, while a further 13 per cent have some college or university experience. Less than 20 per cent of respondents had completed their education at the Leaving Certificate, while just two per cent left school at the age of 16 years or less. It is clear therefore, that Irish journalists are in general a highly educated group. This indicates the extent to which journalism has professionalised in recent years, challenging the increasingly outdated view of journalism as a trade through which one serves an apprentice. The view of one editor expressed ten years ago that 'journalism is essentially an non-academic trade ... I like to think of it as a trade not a profession' (Tom Collins, then editor of the Irish News, quoted in Kenny 1994: 33), seems increasingly anachronistic. Clearly, the present study indicates that nowadays the chances of 
Figure 1: Highest grade completed in school by respondents $(N=112)$

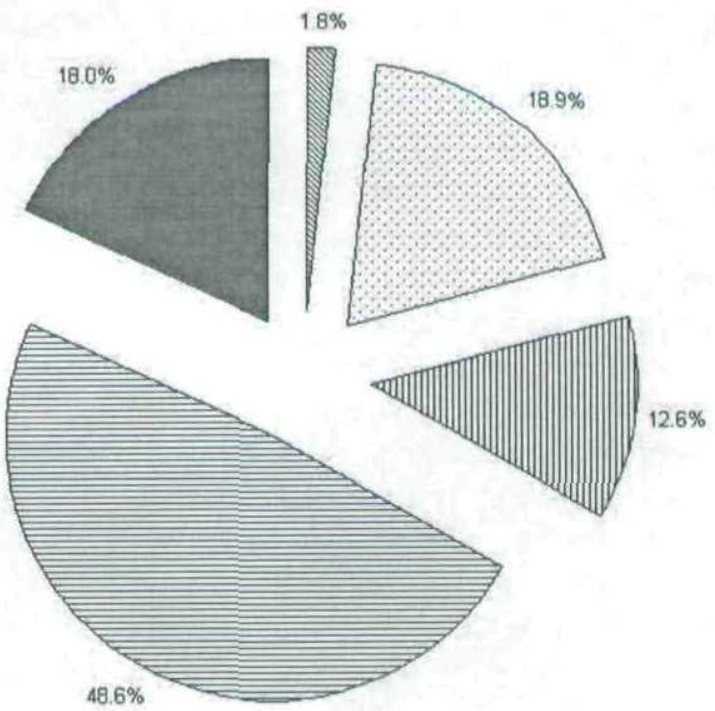

making it onto the bottom rungs of the journalistic ladder are increasingly dependent on third-level educational attainment.

Figure 2 Educational training of Irish journalists expressed in percentages

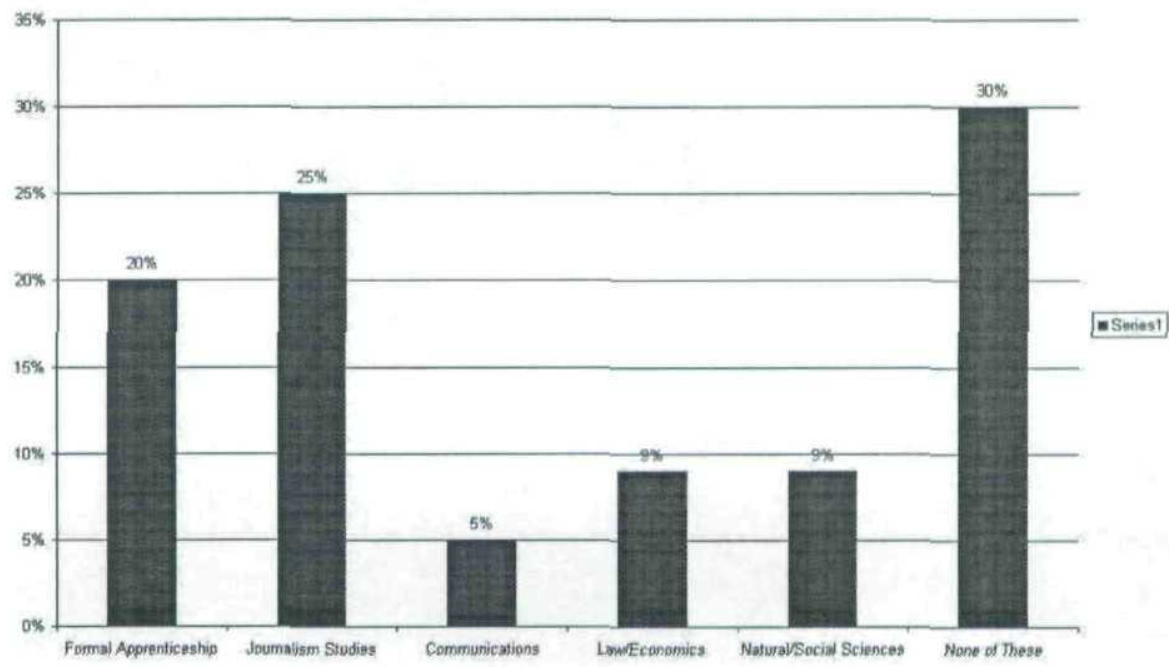


Thirty per cent of Irish journalists have studied journalism/communications at college or university, while 20 per cent have proceeded through the apprenticeship route (see Table 2). The remaining 50 per cent have entered journalism through a variety of routes. Kiberd has argued that one of the major problems with the media lies in the absence of top class training for journalists and the haphazard nature of recruitment to the profession of journalism (1997). As noted above, two-thirds of Irish news journalists have a basic or advanced degree from a third-level institution. This finding would appear to confound the views of both Tom Collins (that journalism is a 'non-academic trade') and confirm those of Kiberd who asserts that Irish journalism 'lacks top class training and is haphazard in his entry procedures'. It is true to say that only half of daily news journalists have received formal training, specifically tailored to their chosen profession. The high level of educational attainment generally among respondents points to a group that is predominantly middle-class, since we know that middle and upper middle classes tend to be overrepresented in Irish third-level education (see Clancy 2001). Furthermore, journalism and media degrees tend to have high entry points level, further militating against those who are not from an advantaged background. If journalists then are largely drawn from the middle classes in society, what particular values and orientations do they bring to their work? This is the question to which we now turn.

\section{Left-right positioning and value orientations of journalists}

Writing in his capacity as editor of a national Sunday newspaper some years ago, Vincent Browne argued that 'Journalists are in the main, very much more liberal in their outlook than is true generally' (1992). This is a view that has been advanced within academic discourse in the United States (see Lichter and Rothman 1986) and voiced many times in public discourse in Ireland, most recently in Kiberd's (1997) edited collection. One of the purposes of the Media and Democracy project is to explore the veracity of this assertion.

Patterson and Donsbach (1996) have analysed their data on political partisanship for the five participating countries in the Media and Democracy study, so it is possible to make some comparisons between their findings and the responses obtained in the Irish module. When asked to place themselves on a scale where 7 is right, 1 is left and 4 is centre, Irish journalists as a group identified more with the left than with the right.

Table 1. The left-right positioning (self-identified) of journalists in six countries

\begin{tabular}{lccccc} 
Italy & Ireland & USA & Germany & Sweden & UK \\
\hline 3.01 & 3.15 & 3.32 & 3.39 & 3.45 & 3.46 \\
$(1.30)$ & $(1.09)$ & $(1.09)$ & $(1.10)$ & $(1.23)$ & $(1.19)$
\end{tabular}

Note: Based on 7-point left-right scales. Respondents were asked 'On a scale where 1 is left, 7 is right and 4 is the centre, where would you place yourself? (Standard deviation is given in parentheses.) 
A substantial majority of journalists in each country placed themselves at or adjacent to the midpoint on the left-right scale. The Irish, with a mean score of 3.15 , were closest to the Italian journalists (3.01) who were the most liberal group of all those surveyed. British and Swedish journalists with average scores of 3.46 and 3.45 , respectively, were the least liberal. The Irish were also more left leaning that either German (3.39) or U.S. (3.32) journalists. However, the Irish are considerably more moderate than their Italian counterparts. Except in Italy where 11 per cent of the respondents placed themselves on the far-left position on the 7-point scale, fewer than five per cent of the respondents in any country took such a position. Hence, the standard deviation scores are low across all the participant countries on the variable of left-right positioning. Only 3.6 per cent of the Irish journalists placed themselves at the extreme left. Sixty-eight per cent of the Irish sample of daily news producers placed themselves left of centre, and no-one placed themselves on the extreme right.

Patterson and Donsbach's analysis of the five-country survey further confirms that in general that journalists view themselves as more liberal than the news organisations for which they work (1996: 458). In all five countries, the mean editorial position of the news organisation as perceived by the journalists was significantly to the right $(\mathrm{p} .<.01)$ of where the journalists placed themselves. In fact, the mean editorial position of news organisations was slightly to the right of centre in three of the five countries, Britain (4.36); Germany (4.27) and Sweden (4.22). By this measure the U.S. news system was the most centrist; the mean editorial position of U.S news organisations (3.98) was at nearly the precise midpoint on the scale. Only in Italy (3.76) did journalists perceive news organisations, collectively, to have a left of centre bias. In Ireland, the mean editorial position of news organisations was 4.22 , slightly to the right of centre, as in Britain, Germany and Sweden. In other words, Irish journalists see the organisations they work for as inherently more conservative than themselves.

It is necessary to be somewhat cautious about inferring political or ideological orientation on the basis of a single-item measure. The definitions of what constitutes 'right' and 'left' have become increasingly blurred in modern democracies with most political parties jockeying for a centrist or 'third way' position. The subjective understanding of 'left' and 'right' labels may also vary from person to person and certainly from country to country. Nevertheless, there are a number of other 'issue' questions we can examine in order to gauge the value orientation of journalists.

One of the primary criticisms levelled against journalists has been the tendency of the media to exclude certain disadvantaged sections of society in its news coverage. Journalist Colm Rapple claims that one third of the population that lives on social welfare has been largely excluded from coverage in the mainstream media (Rapple 1997: 76). In the survey, only 17 per cent of journalists considered that the views of the unemployed were fully represented in their own news organisation, while the same percentage held that the views of 'common working 
people' were given adequate coverage. Only 6.3 per cent of journalists felt that the views of travellers were fully expressed in their news organisations' coverage, while only a small minority, 5.4 per cent, thought the views of gay groups were adequately covered. On the other hand, the key social partners - political parties, trade unions and business interests - were seen to be much more fully represented in media coverage. When asked about representation of the more powerful institutions and social groups in society 59 per cent of respondents felt the views of both Fianna Fáil and Fine Gael to be fully represented, 48 per cent of respondents considered that trades unions' views were fully represented, 38 per cent thought big business was also represented adequately, and 23 per cent of journalists considered the rich to be fully represented in their organisations coverage. Kiberd (1997) has posed the question of whether or not the Irish media are a pluralistic institution. It is clear from our findings that in the view of journalists themselves, not all groups in society receive equal coverage and representation. Rapple has argued that one of the reasons the less powerful in society are under represented is due to 'what news is readily available and a certain degree of habit in what is considered newsworthy' (1997: 75). He claims that newspapers need a steady supply of news and it is those in the establishment who want to manipulate the media generally who have more resources at their command in order to shape and structure news for immediate usage. Therefore, those groups in society who can afford to employ public relations practitioners can manipulate news agendas unlike the less powerful groups whose views are not invested with news friendly copy guaranteed to achieve coverage (1997: 75). The political parties, the business lobby and the trade unions are all powerful operators in the media marketplace, and are clearly at an advantage in pushing their agenda when compared with less organised more poorly resourced constituencies.

The views of Irish journalists on a number of socio-economic issues would suggest that in general, they are politically left-leaning/liberal rather than radical or conservative. There is strong support for old-fashioned state intervention in the economy to combat social exclusion.

Sixty-nine per cent believe that the Government should play a larger direct role in providing good jobs and incomes for the economically disadvantaged. Similarly, over 60 per cent would have a problem with economic growth which conflicted with environmental concerns. On the more abstract issue of the difficulties faced by the Third World, journalists are willing to accept the culpability of the West. Sixtyone per cent agreed with the statement 'The problems of Third World Countries are largely the result of exploitation by the industrialised countries'. On law and order, half of the journalists would not support long prison sentences for those convicted of serious crimes, while a quarter were neutral on the issue.

Even if it is true that 'the agenda to which journalists work gives sparse space to the interests of the poorer sections of our community' (Browne 1992) the survey findings suggest that journalists' own personal views are sympathetic to the marginalised. Irish journalists are thus faced with a dilemma. According to O'Neill 
Figure 3 Response to the item 'The government should play a larger direct role in providing good jobs and incomes for the economically disadvantaged'.

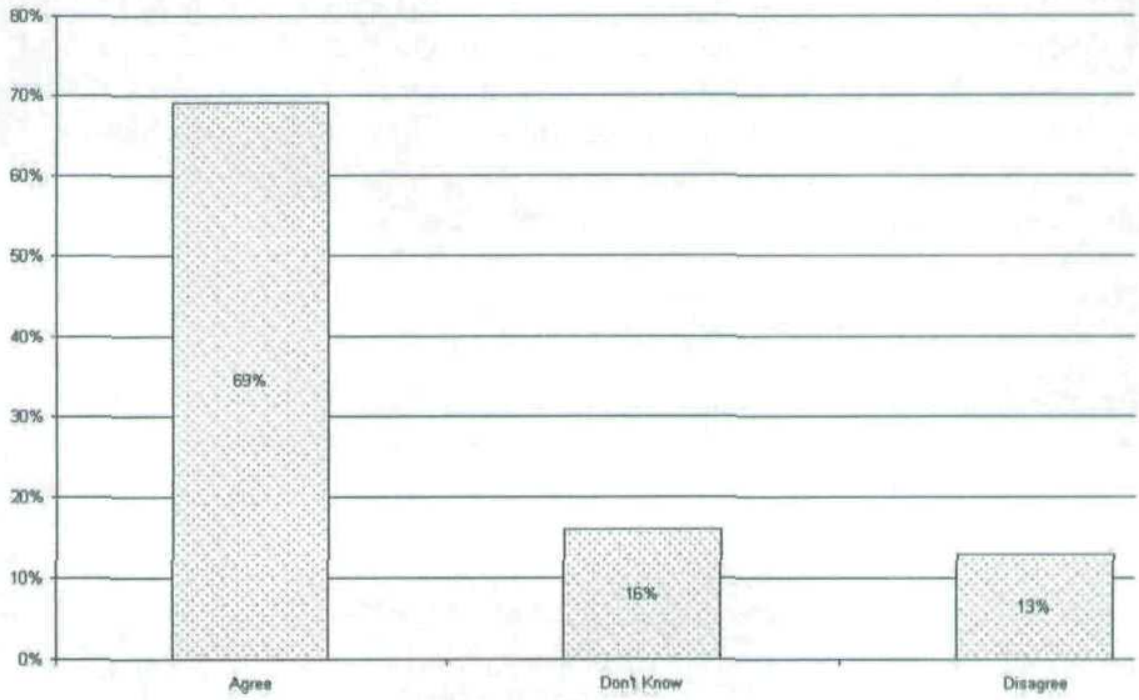

Figure 4 Responses to the item 'The problems of Third World countries are largely the result of exploitation by the industrialised countries'.

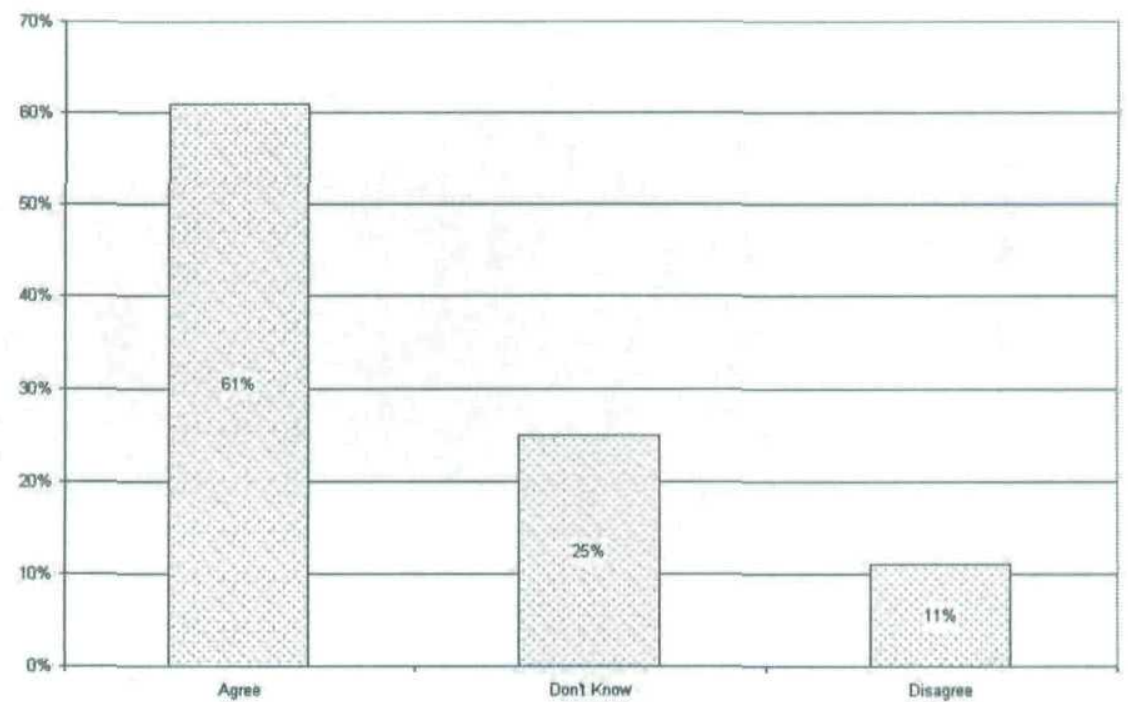


the journalist exists in two worlds: he or she enters a practice that is characterised by a commitment to truth-telling, and at the same time, he or she is an employee who works for a wage and is expected to produce a story of the kind demanded by his or her newspaper or TV station. The nature of such stories is determined by a market with which the journalist might have no sympathy (1992: 27). The Irish journalist who is left of centre politically writes for news organisations and audiences (see below) that in the main are viewed as right of centre. The will to 'tell it like it is' must be constantly balanced against the dictates emanating from within the organisational hierarchy and the demands of the marketplace.

\section{Irish journalists and their audiences}

Michael O'Toole, the former Irish Press journalist suggested in his memoir, More Kicks than Pence (1999), that Irish journalists were 'a breed apart' from ordinary people. A substantial minority (43 per cent) of journalists agreed with this statement, confirming the view that journalists to a great extent perceive a distance between themselves and the audiences they serve. Indeed, a similar proportion (44 per cent) believe that journalists and the public do not share similar views.

Figure 5: Response to item 'Journalists and the public have quite similar views on most issues.'

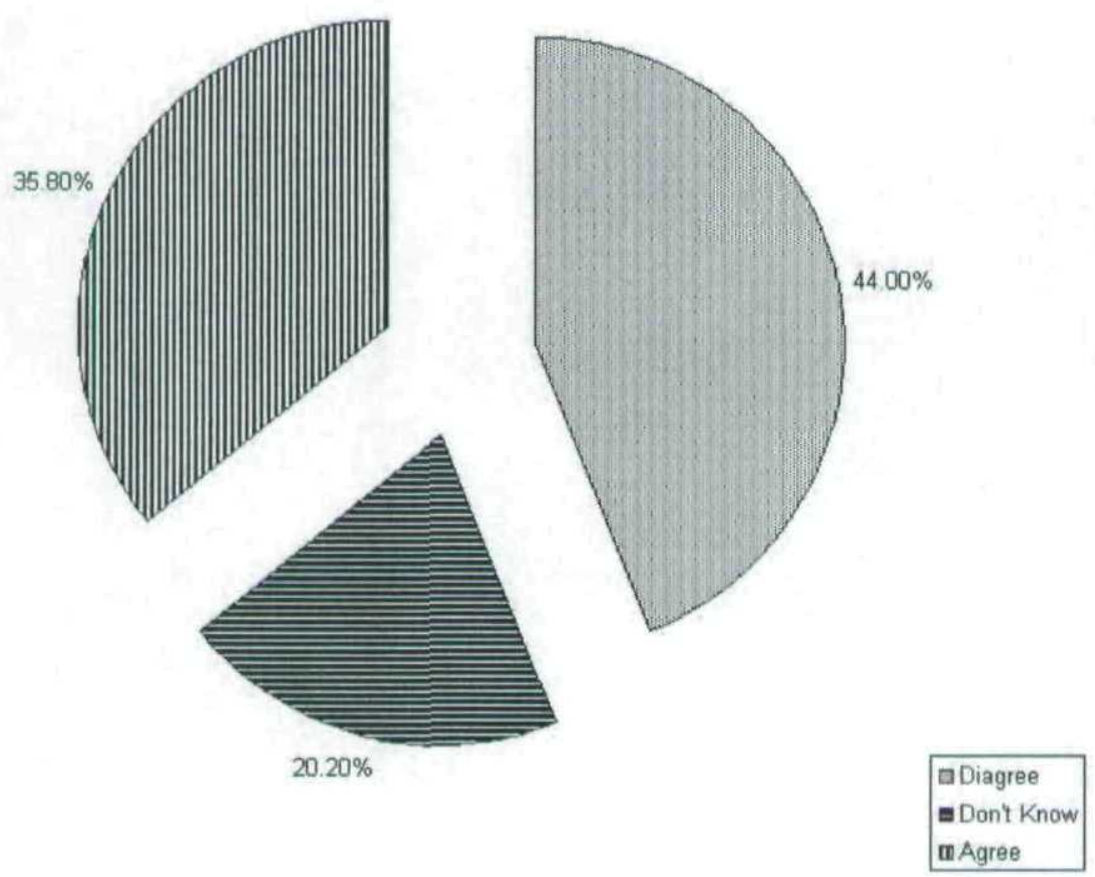


This divergence is brought into sharp relief when we look at the how journalists position their audience on a left-right scale, where 1 represents the left, 4 represents centre and 7 represents the right. Furthermore, journalists in all countries locate themselves to the left of where they perceive their news audience to be. Interestingly, the difference between journalists' mean position on the 7point scales and where they positioned their audience was greatest in Ireland where more than a full point ( 3.15 and 4.48 respectively) separated the means. The only other country to record such a gap between self-perception and perception of the news organisation's audience was the United States (3.32 and 4.47 respectively). The gap between journalists and their news audiences was smallest in Sweden (3.45 and 4.11 respectively) with Italy and Great Britain close behind. In all cases these differences were statistically significant at $\mathrm{p}<.01$. Irish journalists would appear to regard themselves as substantially more liberal than the news audiences that they serve.

Moreover, Irish journalists express considerable independence of mind in relation to the views they personally hold. They see no reason to tailor their journalism so that it fits with the ideas and values expressed by the audience. Indeed, McCullagh points out that 'the available research indicates that, for the most part, journalists know little about their audiences or about their knowledge of current affairs' (2002: 74). Only 11 per cent of Irish journalists agreed with the statement that journalists should not promote ideas and values that have been rejected by the broad public. Thirty-four per cent strongly disagreed. This would suggest that a significant proportion of Irish journalists see themselves as having an agenda-setting role in terms of popularising ideas and values that may be at variance with the views of their audience. Their own views, while not necessarily resonant with those of the audience, are probably affirmed by the views of other like-minded journalists. It is noteworthy that two- thirds of the sample count a journalist among their three closest friends. Indeed, Hagen (1999) has argued that journalists are most responsive to their professional group, and that far exceeds any image they have of the general public.

The divergence between journalists and the audiences they serve is most clearcut when stated political party allegiance is examined. It is particularly instructive to compare this breakdown with data from the Irish Times/MRBI opinion polls. The survey was carried out between April and September 1997. A general election was held on 7 June, 1997. On that morning, The Irish Times published a first ever election day survey which identified (very accurately as it turned out) the first preference positions of the electorate on that day. We can compare data from that public opinion poll with the responses to the question in our study on party preference.

While just over a third of journalists (37.4 per cent) claim to have no political preferences, the next largest group (34.6 per cent) is closest to the Labour Party. Just under three per cent were close to the Progressive Democrats and a similar percentage were close to Sinn Féin. Surprisingly, Green Party supporters at 6.5 per cent 
Figure 6: Response to item 'Of your three best friends or acquaintances how many of them are journalists?'
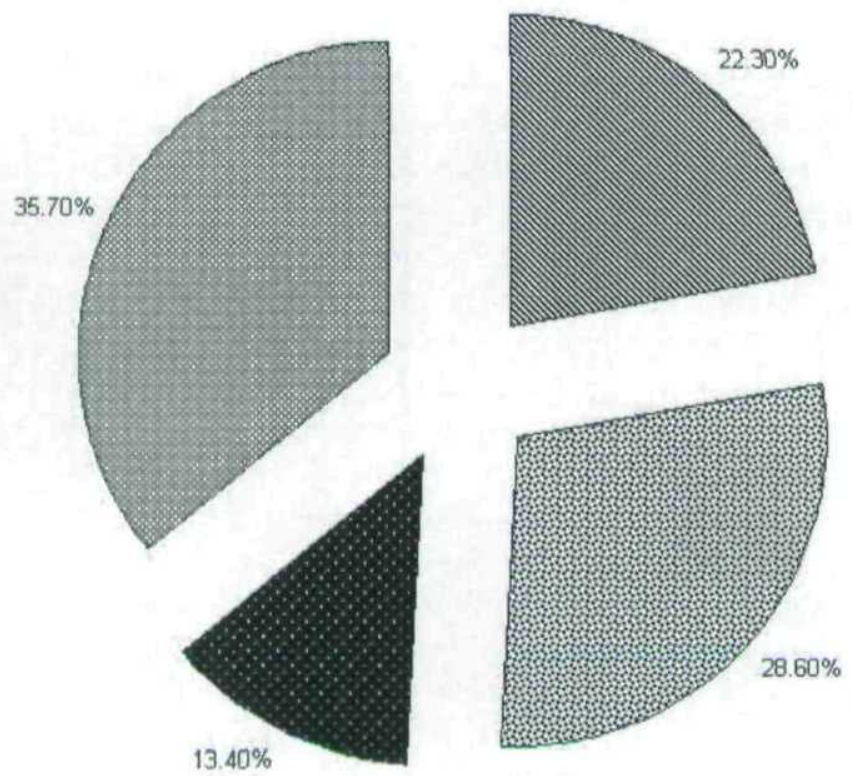

\$ Two are Journalists mOne is a Journalist

- Three are Journalists Gone are Joumalists

Table 2: Response to item 'Generally speaking, which political party are you closest to?'

\begin{tabular}{lrrc}
\hline Party & Frequency & Percent & Valid Percent \\
\hline Fianna Fáil & 6 & 5.4 & 5.6 \\
Fine Gael & 11 & 9.8 & 10.3 \\
PD & 3 & 2.7 & 2.8 \\
Labour Party & 37 & 33.0 & 34.6 \\
Green Party & 7 & 6.3 & 6.5 \\
No Party Affiliation & 40 & 35.7 & 37.4 \\
Other Party (Sinn Féin) & 3 & 2.7 & 2.8 \\
Missing & 5 & 4.5 & 100.0 \\
\hline Total & 112 & 100.0 &
\end{tabular}

Note: figures for Democratic Left supporters have been integrated into Labour Party. Respondents were asked 'Generally speaking, which political party are you closer to?' 
outnumber supporters of Fianna Fáil whose supporters number just over five per cent of daily news journalists. Just over ten per cent of journalists are close to the Fine Gael party. In stark contrast, the June 1997 Irish Times-MRBI poll, shows 44 per cent support for Fianna Fáil, 27 per cent for Fine Gael, 11 per cent for the Labour Party (inclusive of Democratic Left); four per cent for the Progressive Democrats, four per cent for the Green Party, and 11 per cent for others. This demonstrates that in terms of political positioning there appears to be a gap between the stated political preferences of journalists and those of the audiences they serve. Labour Party supporters are highly overrepresented in the media compared to their distribution in the population at large. Supporters of the Green Party are also somewhat overrepresented. Clearly though, the mainstream parties - and in particular Fianna Fáil - are significantly underrepresented in terms of the distribution of their supporters among the national news corps. Nevertheless, it should be reiterated that the largest single group of journalists claim no party preference, probably because they see neutrality as a key element of their journalistic objectivity.

One way that journalists could promote their partisan values is to seek a position with a news organisation which is in the business of promoting the same values (Patterson and Donsbach 1996: 459-60). In Ireland, the opportunities for such employment are very limited. While The Irish Times prides itself on its liberal agenda - 'We are a liberal newspaper and don't pretend to be anything else' (Conor Brady quoted in The Sunday Business Post, 8 February, 1998), the other newspapers in the daily news market tend toward a more right of centre position. RTÉ, the national broadcaster, is prohibited under legislation from taking a partisan view. Fairness and balance are generally accepted norms, and there appear to be sufficient checks in the system (particularly in the post-McKenna Judgement era) to ensure that coverage in the sphere of politics and current affairs is, in general, non-partisan. In contrast to other European countries (where more diversified mass media systems prevail) there is virtually no correlation between Irish journalists' political beliefs and their perception of the editorial position of the news organisation for which they work (.04). In the European news systems as a whole, there is a closer connection between journalists' partisanship and that of their news organisation. The correlation (Pearson's $r$ ) is particularly strong among Italian (.47) and German (.54) journalists who work for the leading national papers, and it is also relatively high among their British (.24) and Swedish (.23) counterparts. It would appear then that journalists' own partisan views are virtually irrelevant in terms of determining the job they hold in either print or broadcasting organisations. This is likely to change only if and when the Irish mass media system becomes more diversified. Overall then the findings of the Irish survey confirm the view that:

the capacity of the personal political preferences of individual journalists to influence what they produce is limited by the realities of the employment situation, by the ideology of the organisations for which they work, and by the structural requirements of their role as professional workers (McCullagh 2002: 74). 
Another avenue which may allow a journalist to pursue a more political goal is to switch from journalism to working for a political party. Journalists are after all 'men and women of opinions-quick on decisions, articulate, skilled at putting them over. Those are political assets too' (Preston 1997). Research suggests that there are close occupational interlinkages between politicians and journalists (Blumer and Gurevitch 1981). Of the journalists who took part in our research, only nine per cent have ever worked full-time in government or politics. This is not surprising, since generally the transition seems to be in the opposite direction with journalists moving on to careers in public relations in the private, governmental or public sectors.

Figure 7: The likelihood of journalists taking a job in government or politics

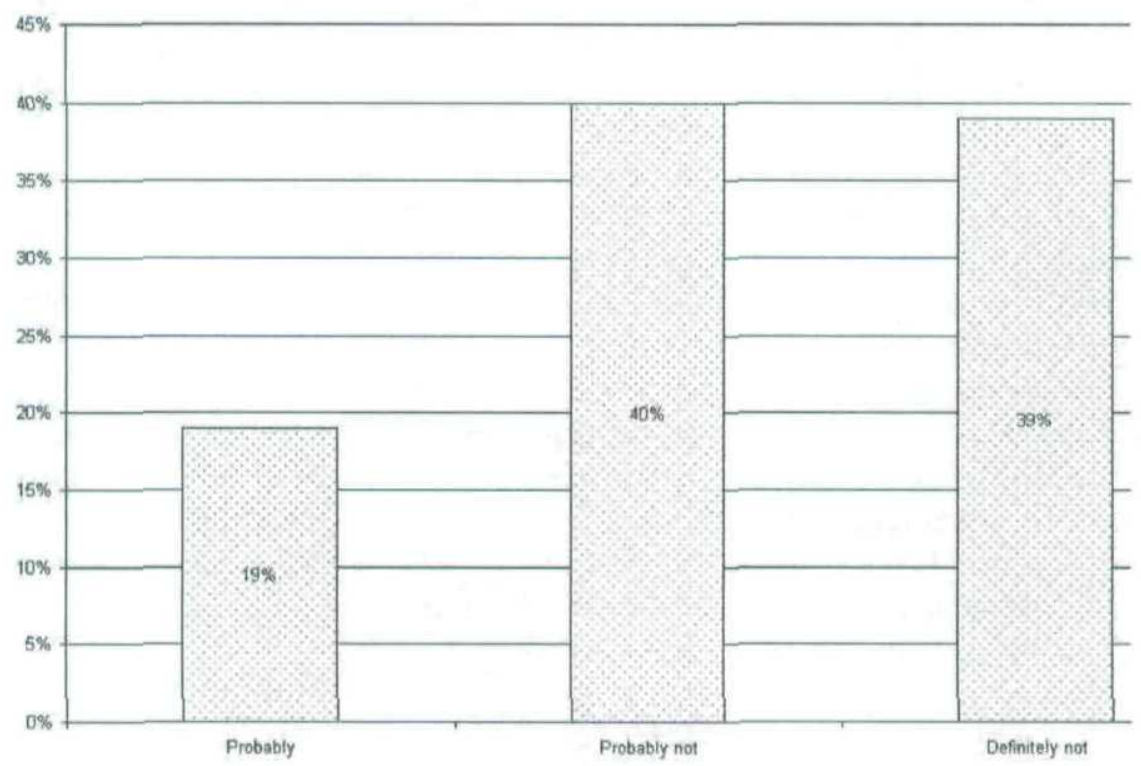

When asked if a suitable job were available in government or politics that offered greater opportunities than the journalist's present job, 79 per cent of respondents said they would 'probably' or 'definitely' not take it. This finding suggests that there is a marked occupational divide between politics and the media in Ireland. This may be partly explained by the fact that the parties most likely to be supported by journalists are also those least likely to be represented in government in recent years. This finding also runs contrary to the public perception of journalism/public affairs linkages which is largely based on high profile transfers out of journalism and into public affairs (and sometimes back to journalism again). The examples of journalists following this trajectory are numerous: Geraldine Kennedy left journalism to become a T.D. for the Progressive Democrats in the 
late 1980s, and is now editor of The Irish Times; Sean Duignan left RTÉ news to work as press secretary to Albert Reynolds, Taoiseach in the early 1990s; economics journalist Shane Kenny became press secretary to John Bruton in the mid1990s and later returned to public service broadcasting; Kathleen O'Meara, a former RTÉ journalist is now a Labour Party Senator and Dáil candidate in Co. Tipperary; Tom Savage, a former journalist, was a press advisor to Albert Reynolds, and is currently a Director of Carr Communications a company that trains politicians for media appearances; John Murray left journalism to work as press secretary to the Progressive Democrats and is now an economics reporter on RTÉ, and former RTÉ news political editor Una Claffey is currently a special advisor to the Taoiseach, Bertie Ahern.

In reality, the linkages between journalists and public affairs may, however, be more indirect than direct. A significant minority (20 per cent) of respondents attested to having at least one or two best friends working in politics or government. These are undoubtedly useful friendships to cultivate for those involved in daily news production. While there appears to be little formal motivation to cross from the media into the political arena, the data nevertheless suggest considerable informal ties between politics and the media.

\section{Conclusion}

In this paper I have attempted to offer some insight into the social composition of the Irish journalist corps, and to their political preferences and value orientations. The population of Irish journalists is in the main a relatively youthful cohort, which is likely to become more gender balanced over time as increasing numbers of women come into the profession. Given the high level of educational attainment, the increasing take up of tailored journalism/media degrees and the fact that many degree programmes have relatively high entry requirements, we can surmise that Irish journalists are predominately drawn from the middle classes. They are entering an occupation that is increasingly professionalised and that is made up of a relatively homogeneous social grouping.

Irish journalists are no different in terms of political positioning from their European counterparts in that they locate themselves slightly to the left of centre. As a group they are not so much radical firebrands, but rather progressive in terms of their beliefs and orientations. They are probably best described as a mainstream group with liberal tendencies (Patterson and Donsbach 1996: 465). They are sympathetic to the plight of the less well off in society, and tend to see solutions to problems like unemployment in structural rather than personal terms. On the whole, they believe that the interests of those sectors of Irish society that are well connected and served by public relations machines, are better represented in their news organisations coverage of politics and public affairs than more marginalised groups.

In terms of their political positioning, journalists see themselves as somewhat at variance with the audience they serve. They see some disjuncture between their 
own values and orientations and those of the general Irish public. This is bound up with their strong sense of themselves as a cohesive group reinforced by the fact that the majority of them count at least one journalist among their closest friends.

Any study of journalistic norms and professional practice must be mindful of 'the constraints imposed by organisations despite the private intentions of individual actors and the inevitability of 'social construction' of reality in any system' (Schudson 1989: 274). Organisational constraints to some degree neutralise any temptation a journalist may have to pursue a personal agenda within his or her news organisations. Most Irish journalists see themselves as more liberal than the organisations for which they work, but this does not prevent them carrying out a professional job on a daily basis. Only a small minority (less than ten per cent) favour a style of advocacy journalism. The gathering, framing and dissemination of facts is always both a political and professional accomplishment. Irish journalists are strongly committed to their sense of professionalism and subscribe to the norm of objectivity. Nevertheless, they are self-aware and understand that their own world-view may be slightly out of kilter with that of both the news organisations they work for and the audiences they serve. This does not imply that they are radically pursuing a subversive agenda. Rather, it is more likely that they shield their professional work from their own political leanings. It is instructive that more than a third of them claim no political allegiance, which may imply that they are apolitical, or that at the very least, they see the rejection of a party allegiance as a professional requirement of the job. Once they enter the profession it appears that their partisan beliefs become secondary to their professional orientation.

\section{Notes}

1. The author gratefully acknowledges a grant from the Irish Social Science Research Council, Royal Irish Academy, which made the study possible. The author also wishes to acknowledge the important contribution made by Caroline O'Kelly, Helen Kelly Browne and Brian Kavanagh to the administration and analysis of the survey data.

2. TV3 was not launched until September 1998.

3. Of respondents, 49.1 per cent work in newspapers, while 50.9 per cent work in the electronic media. The relative parity of the breakdown of respondents by medium of communication reflects the sampling frame used. Given the relative smallness of the sample size, however, I have not distinguished between print and broadcast journalists in presenting survey data in this paper.

\section{References}

Blumler, Jay and Michael Gurevitch 1981 'Politicians and the Press: An Essay on Role Relationships' pp. 467-93 in D. Nimmo and K.R. Sanders (eds), Handbook of Political Communication. London: Sage.

Brady, Conor 1999 'Newspapers, standards, litigation. Is there a better way?' pp. 69-78 in D. Kiberd, (ed.) Media in Ireland: the search for ethical journalism. Dublin: Open Air. 
Browne, Vincent 1992 'The Cardinal: essentially right on the media', Sunday Tribune, June 7. Cassidy, E. (ed.) 2001 'Introduction: Ethical Inquiry and Media Practice', Media and the Marketplace: Ethical perspectives. Dublin: IPA

Clancy, P. 2001 College Entry in Focus: A fourth national survey of access to higher education. Dublin: Higher Education Authority.

Cook, Fay et al. 1983 'Media Effects and Agenda Setting', Public Opinion Quarterly, 47: $16-35$.

Corcoran, Mary P. and Alex White 2000 'Democracy and the Tribunal of Inquiry' pp. 185-96 in M. Peillon and E. Slater (eds) Memories of the Present: Irish Sociological Chronicles, Vol. 2 Dublin: IPA.

Corcoran, Mary P. and Mark O'Brien (eds) forthcoming Censorship and the Democratic State. Dublin: Four Courts Press.

Demuijnck, G. 2001 'Market forces and mass media: competing for an audience of consumers' pp. 164-72 in E. Cassidy (ed.) Media and the Marketplace: Ethical perspectives. Dublin: IPA.

Gamson, W. and Modigliani, A. 1989 'Media Discourse and public opinion on nuclear power: a constructivist approach', American Journal of Sociology, 95: 1-37.

Gans, Herbert 1980 Deciding What's News. London: Constable.

Hagen, I. 1999 'Slaves of the ratings tyranny? Media images of the audience' pp. 130-50 in P. Alasuutari (ed.), Rethinking the Media Audience. London: Sage.

Hallin, D. C. 1985 'The American News Media: a critical theory perspective', pp. 121-46 in J. Forrester (ed.) Critical Theory and Public Life. Cambridge, MA: Harvard University Press.

Horgan, John 2001 Irish Media: A Critical History. London: Routledge.

Kelly, Mary 1983 'Who Controls the Domestic News Agenda?' Paper presented at the Communications and Control Conference, Dublin, April.

Kenny, Ivor 1994 Talking To Ourselves: Conversations with Editors of the Irish News Media. Galway: Kenny's Bookshop.

Kiberd, Damien (ed.) 1997 Media in Ireland: The Search for Diversity. Dublin: Open Air.

Kiberd, Damien 1997 'Have media practitioners a brief to change society?', pp. 33-40 in D. Kiberd, (ed.), Media in Ireland: The Search for Diversity. Dublin: Open Air.

Kiberd, Damien (ed.) 1999 Media in Ireland: The Search for Ethical Journalism. Dublin: Open Air.

Kepplinger, Hans and Renate Kocher 1990 'Professionalism In The Media World?' European Journal of Communication, 5: 285-311.

Let in the Light: Censorship, Secrecy and Democracy. 1993 Dingle: Brandon Press.

Lichter, S.R. and S. Rothman 1986 The Media Elite: America's New Power Brokers. Bethesda, MD: Adler and Adler.

MacArthur, B. 1991 Deadline Sunday: A Life in the Week of the Sunday Times. London: Hodder.

McCombs M. E. and D.L. Shaw 1972 'The Agenda-setting function of the press', Public Opinion Quarterly, 36: 176-87.

McCullagh, C. 2002 Media Power: A Sociological Introduction. Basingstoke: Palgrave.

McQuail, D. 1998 Mass Communication Theory: An Introduction. London: Sage.

Marron, Maria 1995 'How Irish journalists view investigative reporting' in Newspaper Research Journal, 16 (4): 87-102.

Martin, L. 1981 'Government and the News Media', pp. 445-65 in Dan Nimmo and K.R Sanders (eds), Handbook of Political Communication. London: Sage. 
O'Neill, John 1992 'Journalism in the Market place', pp. 25-33 in Andrew Belsey and Ruth F. Chadwick (eds) Ethical Issues in Journalism and the Media. London: Routledge

O'Toole, Michael 1999 More Kicks Than Pence: A Life in Irish Journalism. Dublin: Poolbeg.

Oram, Hugh 1993 Paper Tigers. Belfast: Appletree Press.

Patterson, Thomas E. and Wolfgang Donsbach 1996 'News Decisions: Journalists as Partisan Actors', in Political Communication, 13: 455-68.

Preston, Peter 1997 'Party free of parti pris?' The Observer, 2 March.

Rapple, C. 1997 'Ownership, standards, diversity: a way forward', pp. 68-79 in D. Kiberd (ed.), Media in Ireland: the Search for Diversity. Dublin: Open Air.

Rogers, E. M. and J.W. Dearing 1987 'Agenda-setting research: where has it been? Where is it going?', pp. 555-94 in J. Anderson (ed.) Communication Yearbook 11. Newbury Park, CA: Sage.

Schelsky, Helmut 1975 Die Arbeit tun die anderen: Klassenkampf und Preisterherrschaft der Intellektuellen. Opladen: Wesdeutscher Verlag.

Schlesinger, P. 1978 Putting Reality Together: BBC News, London: Constable.

Schudson, M. 1989 'The Sociology of news production', Media Culture and Society, 11: 263-82.

Schudson, M. 1991 'The Sociology of News Production Revisited' in Curran, J and M. Gurevitch (eds) Mass Media and Society. London: Methuen.

Tuchman, Gaye 1978 Making News: A Study in the Construction of Reality. New York: The Free Press.

Waters, John. 1995. 'Journalists are neither detached nor neutral', The Irish Times, February 7. 
Copyright of Irish Journal of Sociology is the property of Irish Journal of Sociology and its content may not be copied or emailed to multiple sites or posted to a listserv without the copyright holder's express written permission. However, users may print, download, or email articles for individual use. 